\title{
TRET PERSONALITI TERHADAP PRESTASI KERJA DALAM KALANGAN PEGAWAI SUKAN DI UNIVERSITI KEBANGSAAN MALAYSIA
}

\author{
Nik Nabil Safwan Bin Nik Anuay \& Tajul Arifin Bin Muhamad \\ Fakulti Pendidikan, Universiti Kebangsaan Malaysia, Malaysia \\ Jurnal Sains Sukan dan Pendidikan Jasmani 8(1) 13-21, Received: 19 April 2019, Accepted: \\ $20 \mathrm{Mei} 2019$
}

DOI: https://doi.org/10.37134/jsspj.vol8.1.2.2019

\begin{abstract}
Kajian ini bertujuan untuk mengkaji tiga tujuan utama iaitu: (1) mengenal pasti tahap tret personaliti di kalangan pegawai sukan di UKM; (2) untuk mengenal pasti tahap prestasi kerja di kalangan pegawai sukan di UKM; (3) untuk mengkaji hubungan antara tret personaliti dan prestasi kerja di kalangan pegawai sukan di UKM. 44 item Questionnaire Inventori Besar Lima (BFI) diadaptasi daripada John dan Srivastava (1999) yang mempunyai lima dimensi, iaitu Ekstraversi, Kesedaran, Keterbukaan fikiran, Kesetujuan dan Neurotisme. Prestasi kerja diukur dengan menggunakan markah daripada Sistem Penilaian Prestasi (SPPP). Soal selidik ini melibatkan responden daripada kalangan pegawai sukan $(\mathrm{N}=36)$ di UKM. Hasilnya menunjukkan bahawa min tertinggi bagi tret personaliti adalah Keterbukaan fikiran dengan nilai min $(\mathrm{M}=3.70)$ dan tahap prestasi kerja adalah sangat tinggi $(\mathrm{M}$ = 92.98). Di samping itu, hasil analisis korelasi menunjukkan terdapat hubungan yang signifikan antara tret personaliti dan prestasi kerja di kalangan pegawai sukan di UKM ( $\operatorname{sig}=0.010, p<0.05$ ). Kesimpulannya, tret personaliti iaitu keterbukaan fikiran dalam kalangan pegawai sukan amat penting dalam membentuk pekerja agar lebih meningkatkan prestasi dari semasa ke semasa.
\end{abstract}

Kata kunci: tret personaliti, prestasi kerja, pegawai sukan 


\title{
PERSONALITY TRAITS TOWARDS JOB PERFORMANCE AMONG SPORT OFFICER AT NATIONAL UNIVERSITY OF MALAYSIA
}

\begin{abstract}
This present study aimed to investigate three main purposes, which are: (1) to identify the personality traits among sports officer in UKM; (2) to identify job performance among sports officer in UKM; (3) to determine the relationship between personality traits and job performance among sports officer in UKM. The 44 items of Big Five Inventory Questionnaire (BFI) adapted from John and Srivastava (1999) which included five dimension which are Openness To Experience, Conscientiousness, Extraversion, Neuroticism and Agreeableness. Job performance was measured by using marks from Sistem Penilaian Prestasi (SPPP). This questionnaire was administered among $(N=36)$ sports officer in UKM. The result showed the highest mean for personality traits was openness to experience $(M=3.70)$ and the mean of job performance is $(M=92.98)$ which very high. Besides that, the result of Correlation analyses shows there significant relationship between personality traits and job performance among sport officer in UKM (sig $=0.010, p<0.05)$. In conclusion, the personality traits which is openness to experience among sport officer is very important to improve performance over time.
\end{abstract}

Keywords: Personality trait, job performance, sport officer

\section{PENGENALAN}

Proses di antara emosi, interpersonal dan sikap ini dipanggil sebagai personaliti. Personaliti tidak dapat dilihat oleh diri sendiri tetapi mudah ditemui dan dilihat oleh individu lain (Seng, Theng, Ling, Siang \& Yean, 2013). Setiap manusia di dunia mempunyai gaya, sikap, sifat, pendekatan dan cara yang tersendiri. Istilah-istilah ini melambangkan ciri-ciri personaliti diri seseorang yang boleh menjadikan seseorang individu tersebut unik berbanding dengan individu yang lain di dalam pelbagai aspek. Perbezaan ini menyebabkan seseorang individu mempunyai ciri keperibadian dan personaliti yang berbeza yang akan menentukan tingkah laku dan tindakan mereka dalam kehidupan seharian mereka. Personaliti juga merupakan sifat atau ciri keperibadian diri seseorang yang boleh membezakan seseorang individu dengan individu yang lain. Oleh itu, personaliti dapat dikesan dan dilihat dengan jelas mengikut situasi-situasi tertentu.

Tret personaliti merupakan sistem psiko-fizikal yang dinamik dan akan memberi garis panduan kepada individu untuk menentukan ciri-ciri tingkah laku yang bersesuaian dengan persekitaran kemanusiaan dan fizikalnya. Dengan ini, tret personaliti yang dinamik dapat memberi ruang kepada perubahan yang positif dan negatif bergantung kepada fizikal seseorang. Barrick dan Mount (2005) menerangkan bahawa tret personaliti adalah penting kerana boleh meramalkan dan menerangkan tingkah laku di tempat kerja. Minat yang mendalam terhadap kajian dalam personaliti dan prestasi kerja adalah disebabkan oleh kemunculan taksonomi "Big Five" (Jayan, 2006; Detrick \& Chibnall, 2006). Tret personaliti ditakrifkan sebagai bentuk emosi atau motivasi yang menerangkan tingkah laku dalam setiap situasi yang berbeza (Cook, 2005).

Mullins (2005) menyatakan bahawa tret personaliti dapat menjelaskan mengapa individu berkelakuan dengan cara yang tertentu. Setiap individu mempunyai personaliti yang berbeza, iaitu Keterbukaan Fikiran (Openness To Experience), Kesedaran (Conscientiousness), Ekstraversi (Extraversion), Neurotisme (Neuroticism) dan Kesetujuan (Agreeableness) (Nikolaou \& Robertson, 2001). Faktor personaliti Ekstraversi berkaitan dengan individu yang biasanya suka bersantai dan bergaul manakala faktor kesedaran adalah individu yang lebih berhati-hati dalam membuat keputusan, juga memiliki disiplin diri. Seterusnya, faktor kesetujuan merupakan individu yang mempunyai personaliti yang boleh mengelakkan konflik antara pekerja dan majikan. Fleksibel, sopan dan sabar adalah juga tret personaliti yang ada dalam dimensi kesetujuan. Individu yang bijak dalam mencari penyelesaian untuk 
mengatasi tekanan dan masalah dalam organisasi yang dialami olehnya merupakan faktor personaliti neurotisme.

Prestasi kerja bersifat multidimensi dan tingkah laku membentuk prestasi yang berskala dari segi tahap prestasi. Tugas-tugas yang berbeza dilakukan setiap hari menyumbang kepada prestasi kerja secara umum. Walau bagaimanapun, menurut Dehghanan, Abdollahi dan Rezaei (2014), pekerja yang tidak berminat atau kurang bermotivasi untuk melakukan kerja mereka boleh menyebabkan prestasi kerja mereka menurun. Berdasarkan daripada data laporan oleh Gallup State of the Global Workplace, sebanyak 230,000 orang pekerja di 142 negara menunjukkan hanya 13\% pekerja sahaja yang komited di dalam menjalankan tugas mereka di pejabat (New Straits Times, 2016). Dengan ini, prestasi kerja adalah penting dan bergantung kepada beberapa aspek tret personaliti individu tersebut agar dapat menyumbangkan kemahiran mereka untuk mencapai matlamat organisasi. Dalam kajian lepas oleh Dehghanan et al. (2014) menunjukkan seseorang pekerja yang mahir di dalam tugasan mereka tidak semestinya boleh melakukan tugasan mereka secara efisien dan efektif jika personaliti mereka tidak sesuai dengan posisi yang diberikan di pejabat. Tambahan pula, dalam organisasi sukan, pegawaipegawai mempunyai tret personaliti yang berbeza (Dehghanan et al. 2014).

Walau bagaimanapun, terdapat isu yang menyatakan bahawa rata-rata pekerja menghadapi ketidakpuasan dalam kerja mereka kerana tret personaliti yang tidak berapa sesuai dengan pekerjaan yang dilakukan (Seddigh et al. 2016). Para pekerja menyatakan ketidakpuasan hati disebabkan oleh persekitaran tempat kerja yang membosankan dan skop kerja yang tidak berapa sesuai dengan kerja yang diberikan (New Straits Times, 2016). Hal ini demikian kerana pengurusan organisasi majikan yang gagal menjalankan ujian personaliti terlebih dahulu sebelum membuat keputusan untuk mengambil seseorang pekerja (Seddigh et al 2016). Oleh itu, ujian personaliti adalah penting untuk mengukur tingkah laku individu yang boleh membawa kepada potensi prestasi kerja yang tidak boleh dikenal pasti dengan teknik lain. Seterusnya, menurut Dehghanan, Abdollahi dan Rezaei (2014), pekerja yang tidak berminat atau kurang bermotivasi untuk melakukan kerja mereka boleh menyebabkan prestasi kerja mereka menurun. Berdasarkan daripada data laporan oleh Gallup State of the Global Workplace, sebanyak 230,000 orang pekerja di 142 negara menunjukkan hanya 13\% pekerja sahaja yang komited di dalam menjalankan tugas mereka di pejabat (New Straits Times, 2016). Walau bagaimanapun, di Malaysia terdapat sebanyak 99\% pekerja kurang komited dengan tugasan pejabat mereka manakala hanya $11 \%$ sahaja pekerja yang betulbetul komited dengan kerja yang diberikan (New Straits Times, 2016). Perkara ini berlaku kerana mereka langsung tidak berminat dengan pekerjaan mereka dan tidak dapat mengawal tekanan yang dihadapi di tempat kerja mereka. Dengan kurangnya minat terhadap tugasan kerja mereka, maka prestasi kerja mereka akan berkurangan. Dalam kajian lepas oleh Dehghanan et al. (2014) menunjukkan seseorang pekerja yang mahir di dalam tugasan mereka tidak semestinya boleh melakukan tugasan mereka secara efisien dan efektif jika personaliti mereka tidak sesuai dengan posisi yang diberikan di pejabat.

Dengan ini, tingkah laku setiap pekerja adalah berbeza dan boleh mempengaruhi prestasi kerja mereka dalam melaksanakan tugas (Ismail, 2013). Viswesvaran dan Ones (2008) melihat prestasi kerja sebagai pembinaan pusat dalam psikologi individu atau organisasi dan mentakrifkan prestasi kerja sebagai tindakan, tingkah laku, dan hasil yang dapat disumbangkan untuk mencapai matlamat organisasi. Hal ini demikian kerana organisasi akan lebih berjaya dan cenderung dalam mempunyai prestasi cemerlang (Mondak \& Halperin, 2008).

Banyak kajian terkini yang menyokong kajian yang dilakukan oleh Dudley, Orvis, Lebiecki dan Cortina (2006) yang menyatakan bahawa tret personaliti berupaya untuk meramal tingkah laku di tempat kerja. Kajian daripada Abdulwahab (2016) jika seseorang itu berada dalam tugas yang sesuai dengan tret personalitinya, pencapaian dan produktiviti dalam organisasi akan dapat dipertingkatkan. Dengan ini, kejayaan organisasi bergantung kepada prestasi pekerja yang baik. Ryckman (2004) menyatakan personaliti merupakan sesuatu yang dinamik dan merangkumi set yang teratur atau ciri-ciri unik yang dimiliki seseorang individu yang boleh mempengaruhi kelakuan, kognitif dan motivasi individu di dalam pelbagai situasi. Sebagai contoh, personaliti boleh mempengaruhi hasil prestasi kerja seseorang. Situasi 
ini berlaku dikalangan pekerja dalam organisasi dimana mereka mempunyai keupayaan mereka tersendiri dan personaliti yang berbeza yang kemudiannya boleh menghasilkan hasil kerja dan prestasi mereka.

Merujuk kepada Seddigh, Berntson, Platts dan Westerlund (2016) tret personaliti menunjukkan ciri-ciri individu terhadap sesuatu tingkah laku terutama di dalam sesuatu pekerjaan. Di samping itu, majikan perlu mengetahui personaliti individu sebelum mengambil pekerja untuk bekerja dalam organisasi. Prestasi pekerja seseorang dapat dipertingkatkan jika personalitinya sesuai dengan kedudukannya dan peranannya di dalam sesebuah organisasi (Park \& Deitz, 2006). Salah satu sebab pentingnya dalam mengenal pasti tret personaliti adalah untuk memastikan organisasi dapat mencapai visi dan misi dalam tempoh masa yang telah ditetapkan (Lockenhoff, Duberstein, Friedman \& Costa, 2011). Justeru itu, kajian ini bertujuan untuk mengetahui tret personaliti pegawai sukan mempengaruhi pretasi kerja mereka.

\section{METODOLOGI}

\section{Reka Bentuk Kajian}

Kajian yang dijalankan ini menggunakan kaedah soal selidik untuk mengkaji hubungan antara tret personaliti dan prestasi kerja dalam kalangan pegawai pusat sukan Universiti Kebangsaan Malaysia (UKM).

\section{Instrumen Kajian}

Pengumpulan data adalah berdasarkan soal selidik tret personaliti, Big Five Inventory Questionnaire (BFI) daripada John dan Srivastava (1999) yang merangkumi (5) empat aspek, iaitu Keterbukaan Fikiran (Openness To Experience), Kesedaran (Conscientiousness), Ekstraversi (Extraversion), Neurotisme (Neuroticism) dan Kesetujuan (Agreeableness). Manakala, prestasi kerja diukur menggunakan markah penilaian daripada Sistem Penilaian Prestasi Universiti (SPPU).

\section{Responden Kajian}

Responden bagi kajian ini, bilangan populasi dijadikan sebagai sampel kajian. Seramai 36 orang pegawai pusat sukan UKM yang dipilih untuk dijadikan responden dalam kajian ini.

\section{Prosedur Pengumpulan Data}

Pengumpulan data adalah berdasarkan soal selidik yang diedarkan kepada pegawai sukan UKM. Sebelum mendapatkan maklumat kajian ini, penyelidik telah mendapat kebenaran daripada pengarah pusat sukan bagi menjalankan kajian dan mengedarkan soal selidik kepada setiap pegawai pusat sukan UKM. Dengan kelulusan daripada pengarah pusat sukan, penyelidik akan menetapkan tarikh yang sesuai untuk mengedarkan borang soal selidik kepada setiap pegawai sukan bagi mengelakkan sebarang gangguan berkenaan kerja mereka. Responden dikehendaki menjawab soal selidik pada masa tersebut dan menyerahkan semula setelah selesai menjawab. Ketika mengedarkan borang soal selidik, penyelidik menerangkan serba ringkas kepada responden tujuan kajian ini dijalankan dan cara untuk menjawab soal selidik tersebut. Tiada had masa yang diberikan untuk menjawab kesemua soalan tersebut. Penyelidik memberi peluang kepada responden untuk melontarkan segala pertanyaan jika mereka kurang pasti atau tidak memahami soalansoalan yang terdapat dalam borang soal selidik tersebut bagi mengelakkan sebarang kekeliruan. Maklumat yang diperoleh dikumpul dan dianalisis menggunakan perisian Statistic Package for Social Science (SPSS) versi 22 serta penyelidik membuat kesimpulan berdasarkan hasil data yang telah di analisa. 


\section{DAPATAN KAJIAN}

\section{Analisis Deskriptif}

Jadual 1. Analisis Deskriptif Profil Responden

\begin{tabular}{cccc}
\hline Profil Responden & Kumpulan & Kekerapan (n) & Peratus (\%) \\
\hline Jantina & Lelaki & 22 & 61.1 \\
& Perempuan & 14 & 38.9 \\
\hline Umur & 25 tahun ke bawah & 2 & 5.6 \\
& $26-35$ & 16 & 44.4 \\
& $36-45$ & 11 & 30.6 \\
& 46 tahun ke atas & 7 & 19.4 \\
\hline Taraf perkahwinan & Bujang & 4 & 11.1 \\
& Berkahwin & 32 & 88.9 \\
\hline Pendidikan & SPM & 8 & 22.2 \\
& STPM & 15 & 41.7 \\
& Diploma & 11 & 30.6 \\
& Ijazah Sarjana Muda & 2 & 5.6 \\
\hline Tahun berkhidmat & $1-5$ & 4 & 11.1 \\
& $6-10$ & 10 & 27.8 \\
& $11-15$ & 12 & 33.3 \\
& $16-20$ & 5 & 13.9 \\
& 21 tahun ke atas & 5 & 13.9
\end{tabular}

Jadual 1 menunjukkan daripada keseluruhan 36 responden yang terlibat dalam kajian ini, seramai 22 orang atau 61.1 peratus adalah terdiri daripada lelaki, manakala seramai 14 orang atau 38.9 peratus lagi adalah terdiri daripada perempuan. Ini menunjukkan bahawa jumlah responden dari kalangan lelaki melebihi daripada jumlah responden perempuan dalam kajian ini. Berkaitan profil responden mengikut umur pula menunjukkan seramai 2 orang $(5.6 \%)$ berumur 25 tahun ke bawah, seramai 16 orang $(44.4 \%)$ berumur 26 -35 tahun, seramai 11 orang (30.6\%) berumur 36-45 tahun dan seramai 7 orang $(19.4 \%)$ berumur 46 tahun ke atas. Seterusnya, profil responden mengikut taraf perkahwinan menunjukkan seramai 4 orang (11.1\%) adalah bujang, manakala bakinya seramai 32 orang $(88.9 \%)$ adalah berkahwin. Seterusnya, dapat dilihat bahawa majoriti tahap pendidikan tertinggi responden iaitu pada tahap STPM iaitu seramai 15 orang (41.7\%). Diikuti dengan seramai 11 orang (30.6\%) pada tahap Diploma, seramai 8 orang (22.2\%) pada tahap SPM dan seramai 2 orang (5.6\%) pada tahap Ijazah Sarjana Muda. Terakhir, dari segi jangka masa tahun berkhidmat menunjukkan seramai 4 orang $(11.1 \%)$ adalah terdiri daripada $1-$ 5 tahun, seramai 10 orang $(27.8 \%)$ daripada 6 - 10 tahun, seramai 12 orang (33.3\%) daripada $11-15$ tahun, seramai 5 orang (13.9\%) daripada 16 - 20 tahun, dan seramai 5 orang (13.9\%) lagi daripada 21 tahun ke atas. Ini menunjukkan bahawa kebanyakan responden yang terlibat dalam kajian ini dari tahun berkhidmat $11-15$ tahun. 
Jadual 2. Analisis deskriptif tahap tret personaliti pegawai sukan UKM

\begin{tabular}{lccc}
\hline & Min & Sisihan Piawai & Tahap \\
\hline Ekstraversi & 3.08 & 0.263 & Sederhana \\
Neurotisme & 2.98 & 0.340 & Sederhana \\
Kesetujuan & 3.11 & 0.295 & Sederhana \\
Keterbukaan Fikiran & 3.70 & 0.201 & Tinggi \\
Kesedaran & 3.42 & 0.266 & Sederhana \\
\hline Keseluruhan (Tret Personaliti) & $\mathbf{3 . 2 6}$ & $\mathbf{0 . 1 5 1}$ & Sederhana
\end{tabular}

(Tahap: Rendah $=1.00-2.33$, Sederhana $=2.34-3.66$, Tinggi $=3.67-5.00)$

Jadual 2 menunjukkan bahawa skor yang tinggi pula adalah Keterbukaan Fikiran $(M=3.70, S D=0.201)$. Manakala, Ekstraversi $(M=3.08, S D=0.263)$, Neurotisme $(M=2.98, S D=0.340)$, Kesetujuan $(M=$ $3.11, S D=0.295)$ dan Kesedaran $(M=3.42, S D=0.266)$ adalah berada pada tahap yang sederhana. Secara keseluruhan menunjukkan bahawa skor Tret Personaliti $(M=3.26, S D=0.151)$ dalam kalangan pegawai sukan di pusat sukan UKM adalah berada pada tahap yang sederhana. Nilai tertinggi tret personaliti bagi pegawai sukan UKM adalah konstruk keterbukaan fikiran.

Jadual 3. Nilai min dan sisihan piawai bagi tahap prestasi kerja

\begin{tabular}{lccc}
\hline & Min & Sisihan Piawai & Tahap \\
\hline Prestasi Kerja & 92.98 & 2.295 & Sangat tinggi \\
\hline
\end{tabular}

Dapatan tahap prestasi kerja dalam kalangan pegawai sukan di pusat sukan UKM seperti yang dipaparkan dalam Jadual 3 menunjukkan majoriti daripada responden adalah berada pada tahap sangat tinggi iaitu seramai 31 orang $(86.1 \%)$ dan diikuti dengan seramai 5 orang $(13.9 \%)$ pada tahap kuat. Manakala secara keseluruhannya menunjukkan bahawa skor Prestasi Kerja $(M=92.98, S D=2.295)$ dalam kalangan pegawai sukan di pusat sukan UKM adalah berada pada tahap yang sangat tinggi.

\section{Analisis Inferensi}

Jadual 4: Pekali korelasi antara tret personaliti dan prestasi kerja pegawai sukan UKM

\begin{tabular}{lccc}
\hline Hubungan & \multicolumn{2}{c}{ Tret Personaliti } & Interpretasi \\
\cline { 2 - 3 } & $\mathbf{r}$ & Sig. & \\
\hline Prestasi Kerja & $.422^{*}$ & .010 & Lemah \\
\hline
\end{tabular}

Secara keseluruhannya jadual 4 menunjukkan analisis korelasi Pearson menunjukkan tret personaliti (sig $=0.010, \mathrm{p}<0.05)$ mempunyai hubungan yang signifikan dengan prestasi kerja dalam kalangan pegawai sukan di pusat sukan UKM. Analisis korelasi yang telah dijalankan juga menunjukkan wujud hubungan yang positif lemah di antara tret personaliti dan prestasi kerja. 


\section{PERBINCANGAN}

Secara keseluruhannya, kecenderungan tret personliti pegawai sukan ialah pada keterbukaan fikiran. Dapatan kajian menunjukkan min tertinggi bagi tret personaliti adalah dimensi keterbukaan fikiran $(\mathrm{min}=$ 3.70) diikuti dengan kesedaran, kesetujuan, ekstraversi dan neurotisme. Ini menunjukkan kebanyakan tret personaliti pegawai sukan di UKM adalah keterbukaan fikiran. Ini terbukti oleh kajian sebelumnya oleh Othman (2009) menyatakan bahawa individu yang mendapat skor tinggi dalam keterbukaan fikiran untuk mengalami lebih banyak sikap positif terhadap persekitaran organisasi dan idea sendiri. Jenis individu ini akan menjadi inovator yang baik dan mudah untuk menyesuaikan diri dengan teknologi atau persekitaran baru. Selaras dengan kajian lepas menyatakan individu yang lebih berminat untuk terdedah dengan cabaran dan pengalaman baru (Othman, 2009). Di samping itu, kajian juga menyatakan keperibadian jenis ini, individu lebih bertanggungjawab dengan tugas mereka dan melakukan prestasi yang baik dalam organisasi.

Seterusnya, dapatan kajian berkenaan prestasi kerja pegawai sukan UKM secara keseluruhannya menunjukkan bahawa skor Prestasi Kerja $(\min =92.98)$ dalam kalangan pegawai sukan di pusat sukan UKM adalah berada pada tahap yang sangat tinggi. Kajian ini menyokong kajian daripada Tett dan Burnett (2003) yang menyatakan tahap prestasi kerja yang tinggi dapat mengurangkan masalah yang berlaku dalam organisasi dan membetulkan kesilapan dengan cepat. Walau bagaimanapun, dalam tahap ini biasanya pekerja melakukan tugasan melebihi jangkaan kerana lebih kerja keras, keupayaan, dan pengorbanan. Di samping itu, Colquitt, LePine dan Wesson (2010) memberi kenyataan bahawa prestasi kerja adalah salah satu elemen dalam tingkah laku organisasi yang penting dalam mempunyai organisasi yang cekap.

Manakala, perbincangan dapatan kajian inferensi meliputi perbezaan antara tret personaliti dan prestasi kerja berdasarkan jantina dan hubungan antara tret personaliti dan prestasi kerja dalam kalangan pegawai sukan di pusat sukan UKM. Analisis yang digunakan bagi perbezaan adalah ujian-t dan analisis untuk hubungan adalah korelasi Pearson. Ujian-t digunakan untuk melihat perbezaan antara tret personaliti dan prestasi kerja berdasarkan jantina. Analisis ujian-t mendapati tidak terdapat perbezaan antara tret personaliti dan prestasi kerja berdasarkan jantina. Keputusan kajian ini selari dengan kajian yang telah dijalankan oleh Chua Bee Seok (2011). Beliau menjalankan kajian berkenaan perbezaan prestasi kerja berdasarkan faktor demografi, iaitu jantina, status perkahwinan, umur dan pengalaman kerja. Hasil dapatan kajian beliau mendapati jantina tidak mempengaruhi prestasi kerja. Hal ini demikian kerana beliau berpendapat bahawa faktor usaha juga mempengaruhi prestasi kerja.

Selain itu, analisis korelasi Pearson menunjukkan terdapat hubungan yang signifikan antara tret personaliti dan prestasi kerja dalam kalangan pegawai sukan UKM. Dengan ini, keputusan menunjukkan terdapat hubungan positif antara tret personaliti dengan prestasi kerja. Penyelidik mendapati beberapa hasil menunjukkan terdapat hubungan antara tret personaliti dan prestasi kerja yang mana tret personaliti diperlukan untuk meningkatkan keberkesanan prestasi kerja (Seng et al. 2013; Askarian \& Aslami, 2013). Di samping itu, kajian ini menyokong kajian oleh Askarian dan Aslami (2013) yang menyatakan bahawa tret personaliti mempengaruhi prestasi kerja dan meningkatkan kualiti kerja. Sehubungan dengan itu, beliau menyatakan majikan perlu mengenal pasti tret personaliti individu terlebih dahulu sebelum mengambil kerja dalam organisasi. Dengan ini, kecekapan dan kecukupan organisasi pada dasarnya akan ditingkatkan dengan mempertimbangkan personaliti mental dan identiti individu (Seng et al. 2013). 


\section{KESIMPULAN}

Secara keseluruhannya, kajian ini menunjukkan bahawa tret personaliti menyumbang kepada peningkatan prestasi kerja di kalangan pegawai sukan UKM. Kajian ini menyumbang kepada pekerja untuk lebih bermotivasi dan lebih berminat dengan pekerjaan mereka sendiri di tempat kerja. Pemahaman yang baik tentang personaliti dapat mendorong pekerja untuk lebih komited agar dapat bekerja dengan baik untuk mencapai prestasi mereka di dalam sesebuah organisasi. Kemudian, dengan mempunyai pekerja yang bermotivasi, dapat mengurangkan kadar pemberhentian kerja dalam organisasi, meningkatkan kualiti pekerjaan dan memberi manfaat kepada organisasi. Demikian, terdapat beberapa cadangan yang dapat diambil untuk mendapatkan penambahbaikan untuk masa depan yang dicadangkan untuk memperbaiki pada masa hadapan.

1. Kajian berkenaan tret personaliti dan prestasi kerja ini juga boleh dijalankan lebih terperinci lagi dengan menambah pemboleh ubah lainnya. Contoh, tahap kepuasan kerja sebagai pemboleh ubah yang baru.

2. Oleh sebab kajian ini menggunakan kaedah kuantitatif, penyelidik akan datang perlu memberi tumpuan kepada pemerhatian dan wawancara terhadap sampel untuk mendapatkan maklumat terperinci tentang tret personaliti. Penyelidikan tambahan harus dilakukan dengan mengenal pasti perbezaan tret personaliti dalam organisasi yang berbeza. Di samping itu, mungkin ada faktor lain yang tidak termasuk dalam kajian ini dan boleh dikembangkan lebih lanjut.

3. Selain itu, kajian ini hanya memberi tumpuan kepada pegawai sukan di UKM sahaja. Bilangan responden terlalu kecil iaitu 36 responden. Untuk hasil yang lebih baik dan berkesan, penyelidikan masa depan perlu membuat kajian menggunakan sampel yang lebih besar. Penyelidik masa hadapan juga boleh melakukan kajian untuk seluruh institusi di Malaysia daripada memberi tumpuan hanya pada satu institusi sahaja.

\section{RUJUKAN}

Abdulwahab, S. (2016). The relationship between job satisfaction, job performance and employee engagement: An explorative study. Issues in Business management and Economics, 4(1), 1-8.

Askarian, N., \& Eslami, H. (2013). The relationship between personality traits and job performance (case study: Employees of the ministry of education of Kerman). Interdisciplinary Journal of Contemporary Research in Business, 5(8), 322-335.

Barrick, M. R. (2005). Yes, personality matters: Moving on to more important matters. Human performance, 18(4), 359-372.

Chua, B. S. (2011). Hubungan Di Antara Personaliti, Motivasi Dan Prestasi Kerja Dalam Kalangan Belia Sabah (Doctoral dissertation, Universiti Malaysia Sabah, Malaysia).

Colquitt, J., Lepine, J. A., Wesson, M. J., \& Gellatly, I. R. (2011). Organizational behavior: Improving performance and commitment in the workplace (Vol. 375). New York, NY: McGraw-Hill Irwin.

Cook, V. D. (2005). An Investigation of The Construct Validity of The Big Five Construct of Emotional Stability in Relation to Job Performance, Job Satisfaction, and Career Satisfaction. (Doctoral Dissertations, University of Tennessee, Knoxville, US).

Dehghanan, H., \& Rezaei, M. (2014). A study on effect of big five personality traits on emotional intelligence. Management Science Letters, 4(6), 1279-1284.

Detrick, P., \& Chibnall, J. T. (2006). NEO PI-R personality characteristics of high-performing entry-level police officers. Psychological Services, 3(4), 274.

Dudley, N. M., Orvis, K. A., Lebiecki, J. E., \& Cortina, J. M. (2006). A meta-analytic investigation of conscientiousness in the prediction of job performance: Examining the intercorrelations and the incremental validity of narrow traits. Journal of Applied Psychology, 91(1), 40. 
Ismail, M. (2013). Kesan tret personaliti terhadap prestasi kerja dikalangan warga kerja Kementerian Tenaga, Teknologi Hijau dan Air (KeTTHA-FASS Final Project (Psychology).

Jayan, C. (2006). Emotional competence, personality and job attitudes as predictors of job performance. Journal of the Indian Academy of Applied Psychology, 32(2), 135-144.

John, O. P., \& Srivastava, S. (1999). The Big Five trait taxonomy: History, measurement, and theoretical perspectives. Handbook of personality: Theory and research, 2(1999), 102-138.

Löckenhoff, C. E., Duberstein, P. R., Friedman, B., \& Costa Jr, P. T. (2011). Five-factor personality traits and subjective health among caregivers: The role of caregiver strain and self-efficacy. Psychology and Aging, 26(3), 592.

Malaysia. Siri Kertas Penyelidikan Psikologi dan Kesihatan Sosial Bil 2.

Mondak, J. J., \& Halperin, K. D. (2008). A framework for the study of personality and political behaviour. British Journal of Political Science, 38(2), 335-362.

Mullins, L. J. (2007). Management and organisational behaviour. Pearson education.

New Straits Times (2016). Making the workplace 'human'. Retrieved November 1, 2016, from http://www.nst.com.my/news/2016/04/139032/making-workplace-human

Nikolaou, I., \& Robertson IV, I. T. (2001). The five-factor model of personality and work behaviour in Greece. European Journal of Work and Organizational Psychology, 10(2), 161-186.

Othman, F. B. (2009). A Study on personality that influences teaching effectiveness. Unpublished doctoral dissertation. University of Science, Malaysia.

Park, J. E., \& Deitz, G. D. (2006). The effect of working relationship quality on salesperson performance and job satisfaction: Adaptive selling behavior in Korean automobile sales representatives. Journal of Business Research, 59(2), 204-213.

Rothmann, S., \& Coetzer, E. P. (2003). The big five personality dimensions and job performance. SA Journal of Industrial Psychology, 29(1), 68-74.

Ryckman, R. M. (2004). Theories of personality 8th edition. Belmont, CA, US: Wadsworth/Thomson Learning.

Seddigh, A., Berntson, E., Platts, L. G., \& Westerlund, H. (2016). Does personality have a different impact on self-rated distraction, job satisfaction, and job performance in different office types?. PloS one, 11(5), e0155295.

Seng, C. C., Theng, C. S., Ling, L. S., Siang, T. T., \& Yean, W. B. (2013). The Effect Of Big Five Personality On Job Performance: Job Autonomy As The Moderator. UNITAR Theses.

Tett, R. P., \& Burnett, D. D. (2003). A personality trait-based interactionist model of job performance. Journal of Applied Psychology, 88(3), 500.

Viswesvaran, C., \& Ones, D. S. (2000). Perspectives on models of job performance. International Journal of Selection and Assessment, 8(4), 216-226.

\section{झ Nik Nabil Safwan Bin Nik Anuay}

Fakulti Pendidikan

Universiti Kebangsaan Malaysia

Malaysia

Email: niknabilsafwan@gmail.com 